\title{
Reason and Nature-- The Landscape Painting Embodiment of Taoist Morality
}

\author{
Jiang Runyu ${ }^{1}$ \\ ${ }^{1}$ School of Fine Arts, Hunan normal University, Yuelu District, Changsha City, Hunan Province, China. \\ 931473698@qq.com.
}

\begin{abstract}
Chinese landscape painting takes pen-and-ink texturing method as the main formal language, uses different landscape symbols as the way and carrier to express its unique aesthetic interest, and often resides in the unique moral idea of Taoism in the process of painting creation. it makes landscape painting tend to aesthetic function in painting function, incline landscape painting to natural beauty in aesthetic concept, and advocate the speculative nature of painting theory in formal language. In the aesthetics of painting, it is emphasized that landscape painting embodies the spirit of human nature and life. This paper takes the Taoist moral concept as the origin of painting, and combined with the representative work "Journey through Brooks and Mountains" by Fan Kuan (950-1032) in the Northern Song Dynasty, this paper analyzes its theoretical background, formal language, symbolic content and comparison in the history of landscape painting, and explores the Taoist moral concept hidden in the picture narrative of landscape painting and its aesthetic taste from the dimension of Taoist thought.
\end{abstract}

Keywords: landscape painting, Taoism, morality, painting

\section{理性与本性一一道家道德的山水画体现}

\author{
江润宇 1 \\ ${ }^{1}$ 中国湖南省长沙市岳麓区湖南师范大学美术学院 \\ 931473698@qq.com

\section{摘要} \\ 中国的山水绘画以笔墨皴法作为主要的形式语言，以形态各异的山水符号作为表达其独特审美意趣的方式与 \\ 载体, 在绘画创作的过程中也往往寓居着道家独特的道德理念, 在绘画功能上使得山水绘画趋于审美功能, 在 \\ 审美理念上将山水绘画倾向自然美，在形式语言上主张画理的思辨性，在绘画美学上强调山水绘画体现人的本 \\ 性生命精神。本文就道家道德观念作为画学渊源，并结合北宋画家范宽 (950-1032) 的代表作《溪山行旅图》, \\ 分析其理论背景、形式语言、符号内容及在山水画史的比较并从道家思想的维度发掘潜藏于山水画画面叙事中 \\ 的道家道德观念及其所衍生的审美趣味。
}

关键词: 山水画, 道家, 道德, 画学

\section{1.道家道德观念的立足点：自然与自身}

在自先秦以来的中国封建社会思想体系中，迎合 统治阶级意识形态的儒家注重于人与社会之间的道 德观念, 而道家思想中关于 “道德”的定义更偏向于 “人与自身”、“人与自然”两方面。老子的著作《道德 经》绝非讲述人与人的社会关系与行为准则, 而是对 于人自身的思考与人居于宇宙的定位，是在“气化流 行”、“阴阳相成”、“虚实相生”的宇宙观背景中对人的
价值与行为的思考。庄子《德充符》篇也是借王骀、 申徒嘉、叔山无趾、哀骀它一系有生理缺陷之人与丑 人怪人的言行来破除人对形体残缺的偏见并体现人 精神本体的圆满具足。庄子认为对于人而言, “德将为 汝美, 道将为汝居”一道德是人的本然天性, 且人的 道德与天地相通—“天子者, 与天地参。故德配天地, 兼利万物, 与日月并明, 明照四海而不遗微小”。道家 哲学中的“道德”直指人的本性与宇宙的本源, “道”为 自然运行之规律, 即“天道”; “德”即人之本性, 即“人 道”。中国艺术中对于道德理念的体现从未缺席, 音乐 
中“大乐与天地同和，大礼与天地同节”, 绘画中“因知 丹青之妙, 有合造化之功”, 艺术的表现终究指向的是 天地的终极本性之道德。不论是儒家思想中人与社会 的道德观念，还是道家思想中人与自身、人与自然的 “人道”与“天道”观念, 在中国山水画中也都得以体现。

以道家道德的角度看待《溪山行旅图》, 则体现为 理性分析的方式与对人自身本性探讨的目的。范宽所 处北宋时期的思想形态与道德理念已经形成“儒道互 补”的面貌, 一方面人们重视儒家道德理念对于人的 社会现实、社会地位、社会关系与伦理秩序的设计与 思考, 并将这种思考运用于社会的政治实践; 另一方 面, 强调超越世俗, 强调理性化, 以宇宙根本运行规 律理论的道家的道德观念与儒家思想与道德观念形 成互补，如《老子·道经·第五章》中“天地不仁，以万 物为刍狗; 圣人不仁, 以百姓为刍狗。天地之间, 其 犹䝴篇乎? ”显现出老子把视角从人的高度上升到天 地的高度，从“人为”的返归到“自然”的，天地无所偏 爱, 任凭万物自然生长。从天地的高度来看待, 则人 所构建出的人的社会关系与伦理法则则变得无足轻 重, 正是这样的思辨角度, 给予了具有知识教养的山 水画家异于民间画匠的审美意趣。

道家思想从更多地偏向于对“人与自身”与“人与 自然”的探讨, 往往站在超越人的现世生活与社会结 构的角度进行思考, 道德于道家思想而言也异于儒家 源自社会关系的价值取向。我们可以分别从《老子.道 经·第二十五章》与《庄子·德充符》中体会道家思想 对于道德的定义, 相较于儒家道德观念对人在社会关 系中本质与运动规律问题的重视, 道家的道德观念从 宇宙的高度对世界的本质与规律问题进行讨论: “有 物混成, 先天地生, 寂兮胗兮, 独立而不改, 周行而 不殁, 可以为天地母。吾不知其名, 强字之曰道, 强 为之名曰大。大曰逝, 逝曰远, 远曰反。”在老子的理 论中, “道”既是宇宙万事万物的本质, 又是其变动不 居的运动规律, 二者结合的统称, 老子将其命名为 “道”。从发生论上说, 道是万物的源头, 从存在论上 说, 道是万物的本体, 从发展论上说, 道是万物的规 律。而庄子在《德充符》中借外形残缺而德行充足者 体现人的内在性之重要, 而这种内在性也体现了人的 本性, 陈鼓应认为: “能体现宇宙人生的根源性与整体 性的谓之“德”。”由此, 道家的道德理念所指向的, 是 宇宙的本质运行规律及人的价值根源, 因此体现在 “人与自然”与“人与自身”两方面, 从“人与自然”的角 度出发, 体现在宇宙生成的本质及运行的规律, 即 “道”, 从“人与自身”的角度出发, 将人自身客体化, 体现在人的本性及其与宇宙的统一性, 即“德”。《庄 子.知北游》也阐明了道德与人的关系: “若正汝形, 一汝视, 天和将至; 摄汝知, 一汝度, 神将来舍。德 将为汝美, 道将为汝居。汝瞳焉如新生之犊而无求其 故。”在人达到端正形体, 专一视觉, 收玫聪明, 集中 思虑的状态时, 像刚出生的牛犊一样纯真无邪不追求 事故, 这时道将成为人的居所, 德在人身上显现出美 感。山水画中道家的道德理念从理性的角度出发, 意
在体现自然的本性并回归人的本性。

\section{2.道家道德的画学与画面体现}

\section{1 以“画形”求“画理”}

在这样的道德观念基础上, 人的思考对象则转向 了宇宙本质及其规律，理性化的思辨分析、对“道”与 “理”的追求。在表现自然的山水画中，对“画理”的思 考与表现成为画家构思作品的重要部分。如与范宽同 处北宋的苏轼曾言: “余尝论画, 以为人禽宫室器用皆 有常形, 至于山石竹木水波烟云, 虽无常形而有常理。 常形之失, 人皆知之; 常理之不当, 虽晓画者有不知。” 苏轻认为在画面表现形象的背后还有“理”的存在, “形”是易于认识的，所以形有所偏差时观画者很容易 发掘, “理”是难以把握的, 当画理没有恰当体现时, 常常通晓绘画之士也不一定能发觉。“形”与“理”的关 系, 就如同“现象”与“本质”一般, 山水画画家常常在 用笔墨描画自然景物现象的同时，也想以笔墨捕捉客 观外在世界的本质与规律, 这也与道家思想中以宇宙 本质及运行规律为思考对象的视点一致。

重“画理”的绘画审美理念既表现在对“画理”与自 然物理法则的遵循，另一方面也强调“画理”自身对自 然物理法则的超越性, 沈括在《梦溪笔谈》也记载了 这类以“画理”的标准欣赏与创作绘画的具体事件: “欧阳公尝得一古画牡丹从, 其下有一猫, 未知其精粗。 丞相正肃吴公与欧公姻家, 一见曰: ‘此正午牡丹也。 何以明之? 其花披哆而色燥, 此日中时花也。猫眼黑 睛如线, 此正午猫眼也。有带露花, 则房玫而色泽。 猫眼早暮则睛圆, 日渐中狭长，正午则如一线耳。” 吴正肃以真实世界的物理运动规律分析画面世界中 的意象, 以牡丹在不同时间样貌的差异与猫眼旦暮时 分眸子的圆狭分析画面中独立的时间因素, 正是因为 这一时期普遍对“理”的追求提供了新的视角。又以山 水画创作“大都山水之法, 盖以大观小, 如人观假山耳。 若同真山之法, 以下望上, 只合见一重山, 岂可重重 悉见”的构图方式对李成画面重山上亭馆塔楼“仰画 飞檐”的独特面貌作出批评, 认为“李君盖不知以大观 小之法, 其间折高折远, 自有妙理, 岂在掀屋角也”, 应以“以大观小”的视角统筹画面, 而不只是重现人的 “以小观大”。以人的视角看待自然物象必然受到物理 法则的限制与制约, 而画面内容作为画家主观创造的 意象世界, 并不一定要完全遵循现实世界的物理法则, 画家对画面中“画理”的把握又是对现实世界物理法 则的一种超越。在此, “以大观小”便是不受人的视角 的限制仁中区以玄览, 站立天地之中览观万物, 将广 衰的山川囊括于画者胸臆, 画中意象虽仍是山水, 但 又超越了现实世界的自然山水，显现着人对自然的关 照, 将人的主观选择与自然的客观规律相结合, “折高 折远”的“妙理”便在此得以彰显。此外, 郭熙“真山水 之川谷, 远望之以取其势, 近看之以取其质”、“画见 其大意而不为刻画之迹, 则烟岗之景象正矣”也都体 现着同样的审美理念。 


\section{2 人的“去主体性”}

山水画面貌从魏晋的“人大于山，水不容泛”历经 隋唐五代发展至北宋时期范宽《溪山行旅图》中人小 如虫㸓一眼不可见, 其中人的元素在画面中的变化极 大, 而这一变化也正如思想中儒家道德理念向道家道 德理念的转向一样, 当画面中人的要素与比例大于山 水时, 自然景物成为人的陪祄, 画面以人的主体性表 现为主, 也蕴含了人的社会关系与伦理观念, 如同时 也体现了人对“自然”思想与细节表现两方面的忽视， 我们可以在顾恺之《洛神赋图》的宋人摹本中看出。 魏晋时期山水主要处于人物的背景，但宗炳的“卧游 说”与 “畅神说”能说明山水在画面中已经成为人们的 审美对象。至隋唐时期自然的构成部分被放大，人物 比例被缩小, 画面中自然元素仍然没有完全成为独立 的审美客体, 画面中占比较大的自然山水仍然成为表 现画面中人物活动的陪祄与背景, 如李思训《江帆楼 阁图》中大面积的山水中用朱砂色粉饰楼阁突出中心 任务的活动场域, 李昭道的《明皇幸蜀图》也是以宏 大的山水景观作为皇家人物出行活动的叙事背景。唐 代是自信开放的朝代, 皇室多有胡人血统, 在文化上 兼收并蓄, 在外交、军事、政治上都具强势, 所以在 绘画上体现在强调人的主体性与主观性, 以宏大的山 水作为人物活动的背景陪祄。但是在内外逢源的唐朝 远去以后, 北宋时期相较而言有内无外, 在外交上外 辱不断, 文化观念上失去了唐朝的盛世气象, 只有对 内发展文化, 提炼思想, 在思想上对人的主体性重新 思考, 北宋时期理学的出现是这类思想发展的成果。 较范宽所处年代晚一世纪的朱喜(1130-1200)提出“理 气论”, 认为“理”是形而上者且先于自然现象与社会 现象而存在, 是事物发展的规律与准则, “存天理, 灭 人欲” 虽不是朱喜所提出, 却是其思想的重要主张, 宋 代的理学思想者主张革除超出人基本需求欲望的贪 欲与私欲, 人如果被自己的欲望所蒙蔽就看不到自己 的真实面貌, 体会不到天地之理。朱喜言: “去其气质 之偏, 物欲之蔽, 以复其性, 以尽其伦。”正是要去除 物欲、私欲、贪欲的遮蔽才能恢复人的本性, 体会天 地的至理。唐代山水作为人物活动的陪祄, 也体现了 人对自然的征服欲与占有欲, 人与自然的关系是支配 与被支配的关系, 人类征服自然, 占有自然, 自然山 水成为人的财富、疆域、领土、资源。唐末五代的战 乱使得人们动摇了对自身主体性的自信, 并重新思考 人与自然的关系, 这种思考在宋代山水画的道德理念 中得以显现, 体现在其对人的“去主体性” 的创作理念 中。

宋代文人画家一方面以这种审美意趣作为创作 理念进行创作实践, 另一方面也以此作为审美理念追 认前人的绘画作品, 如《宣和画谱. 山水叙论》中记载: “盖昔人以泉石膏育, 烟霞㽽疾, 为幽人隐士之诮, 是 则山水之于画, 市之于康嘼, 世目未必售也。”山水画 中人物的组成部分不再成为占据画面的主体, 在情感 表现上, 不再体现人对自然的征服欲与占有欲, 取而 代之的是人居于山水自然之中, 或体现纵情自然的文
人诗意, 或体现平常生活的种种情节; 在人物题材上, 自以往常见的神话人物、历史人物、皇室人物以外, 表现社会底层的士农工商世俗生活的人物题材愈发 常见; 在具体表现上，人物的绘制也更为简练，与山 水一同裉去了绚丽的色彩, 仅仅用几根精炼的线条绘 制人物的动态与神情, 人成为整体自然山水中的一个 组成部分。

在《溪山行旅图》中这一点体现的尤为明显, 在 纵深极大的整幅画面中，人物的部分仅有近景右下部 分的两名旅人与一驴队，前者扬鞭领队，后者压队紧 跟, 仅像是普通商队赶路时的场景, 并没有额外的故 事情节或是寓意。范宽在此所要表现的, 并非典故或 是先贤, 而是崇山之中偶有行人偶见生气的生动场面。 在这样的场面中, 人不是自然的主宰与支配者, 而成 为自然中的过客，人物的美感从主体美成为了局部美， 成为丰富画面, 为不变的山水带来变动生机的构成元 素。

在道家道德理念的影响下，画面中人物部分的变 化并不是要否定人的主体性, 而是要还原人居于广衰 无垠宇宙之中的真实样貌, 如苏轼在《赤壁赋》中对 以自身所代表的无数人类个体的描述：“寄蜉蝣于天 地, 渺沧海之一粟。哀吾生之须且, 羡长江之无穷。”, 北宋时期山水画家与文人在文学艺术与绘画艺术中, 都表现认识到人无论在时间还是空间上都具有有限 性的事实, 以《溪山行旅图》、《早春图》为代表的北 宋山水画中在人物与自然山水在大小上的安排也印 证了人对自身空间上有限性的认知。正是在这样的理 论背景下，五代北宋以来山水画创作通过对色彩运用 的减少、对笔墨技法的研究、对人物部分表现的变化 三方面来实现表现自然物象本质的目标, 将山水画创 作回归到以道家道德理念为基础的对人与自然本性 的思考。

\section{3 以墨代色的“求真”形式}

道家道德观念强调以平淡为追求的审美理想, 在 绘画上表现为对自然描绘数量的增多、内容的详尽与 细节的丰富及对人的主体性表现的减弱, 对自然的描 绘中不再蕴含人对自然的征服与占有, 画面中人的元 素与自然的元素不再具有支配与被支配的关系, 而是 更多地体现人对自然的理解。以“平淡”为核心的审美 理想在山水画中具体表现为五彩颜色的减褪、山水表 现技法的多样化与画面中人物元素的弱化。

第一, 山水画中色彩的运用在宋代也明显减少, 以墨色代五色, “墨分五彩”一观念的含义的转变可以 体现这一点。唐代张彦远认为“草木数荣, 不待丹碌之 采; 云雪飘扬, 不待铅粉而白; 山不待空青而翠, 凤 不待五色而綷。是故运墨而五色具, 谓之得意。”用墨 铺陈大体后就会呈现青、赤、白、绿等颜色, 不必再 假借颜料来表现五色，而到宋代以后则多指浓淡不同 的墨色。这样的转变正是为了契合对平淡的审美追求, 老子认为“五色令人目盲, 五音令人耳狵, 五味令人口 
爽, 驰骋略猎令人心发狂, 难得之货令人行妨。”过多 的颜色会眩惑人的眼睛, 过多的声音会纷乱人的感官, 宋代山水画将绚丽的色彩从画面中抽离, 是因为过度 的颜色会阻碍人们发现与表现山水的真实样貌，甚至 遮蔽人们看待事物真实样貌的眼睛, 宋代山水画选择 以纯粹的水墨来表现, 正是要祛除五色对人的遮蔽, 表现山水的本来面貌。在这样的创作观念与审美观念 中, 山水画创作的价值取向由表现自然物象（现象） 转变成表现山水真实样貌 (本质), 这种思考在五代时 期就已初见端倪, 荆浩在《笔法记》中借石鼓岩舅之 口提出了“度物象而取其真”的绘画主张, 将“真”与“似” 相对立, “似者, 得其形遗其气, 真者, 气质俱盛。” 认为空有形似则失去了表现对象的“气”, 而在自先秦 以来的哲学观念中, “气”是构成万物的物质基础, 失 去了“气”也即失去了所要表现的本质, “度物象而取 其真”的绘画主张正是要在绘画中通过自然物象来表 现其运动的本质与规律。另外, 荆浩借石鼓岩舅之口 提出了“嗜欲者, 生之贼也。名贤纵乐琴书, 图画代去 杂欲”的绘画功能, 认为绘画创作具有去除杂欲的功 能, 这样的理论在北宋思想史与山水画创作的影响愈 来愈深, 画家通过山水画创作洗涤心智, 去除杂欲, 实现平淡的审美理想, 认为客观存在的“理”高于人的 主观表现, 只有通过对“画理”的掌握才能表现自然的 真实样貌, 传为王维所作的《山水决》中提出了北宋 时期山水画的最终价值取向——肇自然之性，成造 化之工”, 即通过山水画体悟自然赋予人的的本性, 在 山水画中体现自然山川鬼斧神工的奥妙。

第二, 山水技法的多样化即彼法的多样化, 五代 北宋是山水皴法的拓展时期, 结束了勾勒填色的单一 画法, 画家将目光转向了山水树石的结构特征与纹理 特点, 并抽象提炼成以竬擦为主要方式的绘画语言, “北宋三大家”皆以创新独特的彼法形成了自身独特 的绘画面貌, 各类誜法的形成既是画家的独特创造, 又源于画家对自然的仔细观察, 符合所描绘对象的真 实特征, 因此山水画创作也成为了画家观察体会自然 之“理”的一种方式。李成以“卷云郓”表现寒林平野, 范宽以“雨点变”表现关中崇山，董源以“披麻皴”表现 潇湘幽远, 三者各自的独特皴法都成为后世学习山水 画的重要师法对象, 成为千百年来山水画的重要语言。 就《溪山行旅图》而言, 显然范宽要表现的是关陕地 区的景色, 正是因为范宽对当地山石树木的饱游饫看, 其“居山林间, 常危坐终日, 纵目四顾, 以求其趣。” 范宽常纵身于山水之中, 远观细察, 得其趣味, 将关 陕崇山峻岭之貌了然于胸, 抽象提炼并点画而出。其 独特的“雨点竬”正是为了契合关中地貌山势起伏的 层峦叠嶂中大面积裸露在外的山石表面而形成的, 并 极好地表现出了关中山石崎岖不平质感鲜明的特点。 在满足对自然山水物象形体表达的同时进行了高度 提炼的抽象概括, 既是对真实自然的写照, 又显现出 作者以真实的眼光洞察自然的神思。

\section{3.结论}

综上所述, 道家道德观念在山水画的创作与欣赏 过程中将作者与读者的目光从社会转向了人自身与 自然之中, 给予了山水画家以独立的审美眼光面对自 然山水以获得独特的艺术情感, 并在此基础上结合生 活经验与逻辑思辨进行理性地形象构思，虽然带有一 定的阶级局限性, 主要限于受过教育的文人画家群体, 但仍然对于山水画形式语言、画面风格、审美理念的 探索与发展起着重要的推动作用, 在形式语言上, 道 家道德观念体现在山水绘画中色彩的褪去与纯粹水 墨形式的盛行; 在画面风格上，道家道德观念体现在 山水绘画中平淡求真的气象追求; 在审美理念上, 道 家道德观念在山水绘画中体现在对画理的思辨与对 人物元素表现的“去主体化”上，在就此而言，道家道 德观为山水绘画的发展提供了坚实且丰富的理论基 础。

\section{REFERENCES}

[1] Yu, J. (2015) A grand view of the theory of Chinese painting in the past dynasties. The first part, the Theory of painting from the pre-Qin Dynasty to the five dynasties. Jiangsu Phoenix Art Publishing House, Nanjing.

[2] Yu, J. (2015) A grand view of the theory of Chinese painting in the past dynasties. The second part, the theory of painting in the Song Dynasty. Jiangsu Phoenix Art Publishing House, Nanjing.

[3] Chen, G. (2003) Lao Tzu Modern translation. Commercial Press, Beijing

[4] Chen, G. (2007) Chuang Tzu Modern translation. Commercial Press, Beijing

[5] Zhu, X. (2002) Chu Hsi -The collected works. Shanghai Chinese Classics Publishing House, Shanghai

[6] Su, S. (1986) Su Shi - The Collected Works. Zhonghua Book Company, Beijing.

[7] Zhou, Z. (2013) The Literary Mind and The Carving of Dragons Modern translation. Zhonghua Book Company, Beijing. 